\title{
Successfully Incorporating Writing Across the Curriculum with Advanced Writing in Nursing
}

Karlen E. Luthy

Brigham Young University - Provo

Noillow theters and additional works at: https://scholarsarchive.byu.edu/facpub

art.dfąeetterer Nursing Commons

Brigham Young University - Provo, jane_lassetter@byu.edu

\section{Quriginalaburbtiøation Citation}

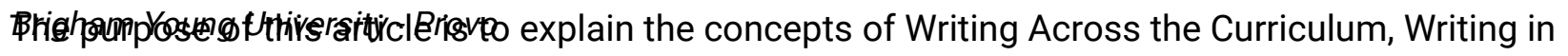
the Disciplines, and Writing to Learn, and to describe the incorporation of advanced writing into a baccalaureate nursing program and provide suggestions for accessing resources and promoting success. The goals of incorporating Writing Across the Curriculum, Writing in the Disciplines, and Writing to Learn concepts into nursing curriculum are to assist nursing students to achieve competence in clinically relevant writing assignments; to demonstrate critical thinking and communication skills, both oral and written; to execute useful literature searches; to read and understand research reports; and to encourage the incorporation of evidence into clinical practice. With a strong and established writing foundation, nursing students will be more successful in written and oral communication during their nursing program and throughout their nursing career.

\section{BYU ScholarsArchive Citation}

Luthy, Karlen E.; Peterson, Neil E.; Lassetter, Jane H.; and Callister, Lynn C., "Successfully Incorporating Writing Across the Curriculum with Advanced Writing in Nursing" (2009). Faculty Publications. 5182. https://scholarsarchive.byu.edu/facpub/5182

This Peer-Reviewed Article is brought to you for free and open access by BYU ScholarsArchive. It has been accepted for inclusion in Faculty Publications by an authorized administrator of BYU ScholarsArchive. For more information, please contact ellen_amatangelo@byu.edu. 


\title{
Successfully Incorporating Writing Across the Curriculum with Advanced Writing in Nursing
}

\author{
Karlen E. Luthy, DNP, APRN; Neil E. Peterson, BS, RN; Jane H. Lassetter, PhD, RN; and \\ Lynn C. Callister, PhD, RN, FAAN
}

\begin{abstract}
The purpose of this article is to explain the concepts of Writing Across the Curriculum, Writing in the Disciplines, and Writing to Learn, and to describe the incorporation of advanced writing into a baccalaureate nursing program and provide suggestions for accessing resources and promoting success. The goals of incorporating Writing Across the Curriculum, Writing in the Disciplines, and Writing to Learn concepts into nursing curriculum are to assist nursing students to achieve competence in clinically relevant writing assignments; to demonstrate critical thinking and communication skills, both oral and written; to execute useful literature searches; to read and understand research reports; and to encourage the incorporation of evidence into clinical practice. With a strong and established writing foundation, nursing students will be more successful in written and oral communication during their nursing program and throughout their nursing career.
\end{abstract}

\footnotetext{
Received: September 22, 2006

Accepted: May 11, 2007

Dr. Luthy is Assistant Professor, Dr. Lassetter is Associate Professor, and Dr. Callister is Professor, Brigham Young University, Provo, Utah; Mr. Peterson is a registered nurse, Cleveland Clinic, Cleveland, Ohio.

Address correspondence to Karlen E. Luthy, DNP, APRN, Assistant Professor, 355 SWKT, College of Nursing, Brigham Young University, Provo, UT 84602-5432; e-mail: beth_luthy@byu.edu.
}

$\mathrm{W}$ riting Across the Curriculum (WAC) is a national pedagogical movement that emerged during the 1980s in response to a perceived literary deficiency among college students (Slimmer, 1992). The WAC premise currently maintains that writing is a valuable learning tool, helping college students to better synthesize, analyze, and apply knowledge specific to their discipline (Lashley \& Wittstadt, 1993). An approach typically found in WAC designated courses, Writing in the Disciplines (WID) acknowledges that each discipline, including nursing, has its own language and style (Lassetter, Luthy, Sutherland, $\&$ Callister, 2005). The production of clear, accurate and relevant writing is an essential competency in nursing (American Association of Colleges of Nursing, 1998). By incorporating assignments such as Writing to Learn (WTL), faculty help nursing students improve their writing skills and understand the course material more completely, and they encourage critical thinking. The ability to communicate clearly and effectively is critical in the provision of quality health care (Callister, 1993; Callister, Matsumura, Lookinland, Mangum, \& Loucks, 2005). Thus, nursing programs need to incorporate advanced writing into core nursing curriculum to enable students to more fully participate in academic discourse.

Like many nursing schools nationwide, the Brigham Young University (BYU) College of Nursing integrates WAC, WID, and WTL concepts into our baccalaureate degree program by assigning advanced writing course- work throughout the curriculum. In addition, advanced writing skills are focused on and more fully developed in the Evidence Based Practice in Nursing (second semester) and Nursing Ethics (third semester) courses, combining nursing core curriculum credit with upper-level English credit. The primary goals of incorporating WAC, WID, and WTL concepts into nursing curriculum are to help nursing students:

- Achieve competence in clinically relevant writing assignments.

- Demonstrate critical thinking and communication skills, both oral and written.

- Execute useful literature searches.

- Read and understand research reports.

- Encourage the incorporation of evidence into clinical practice.

The purpose of this article is to explain the concepts of WAC, WID, and WTL, and to describe the incorporation of advanced writing into a baccalaureate nursing program, providing suggestions for resources and promoting success.

\section{Writing Across the Curriculum}

Since its emersion almost 30 years ago, the basic philosophy behind the WAC movement remains. Essentially, the basic principles underpinning WAC (Kiefer \& Colorado State University [CSU], 2006b) support that:

- Writing is not merely the responsibility of the English department, but of the entire academic community. 
- Writing must be integrated across departmental boundaries to promote student writing skill.

- Writing must be a continuous process, integrated into all 4 years of undergraduate education.

- The very act of writing promotes student learning.

- Only by practicing writing within a specific discipline will students begin to effectively communicate within their discipline.

Writing seminars for faculty and teaching assistants and access to Writing Fellows have been valuable writing resources for the nursing faculty at BYU. These programs are offered at no cost to the BYU College of Nursing and are sponsored by the College of Undergraduate Education. Recognizing that not all universities and colleges have access to these specific resources, nursing faculty can still successfully integrate WAC into the nursing curriculum by making a few resource substitutions.

The Writing Matters faculty seminar at BYU is a 1-week conference to increase faculty confidence with WAC. Incorporating WAC concepts into a nursing curriculum takes effort. Without question, the emphasis on WAC has been the cause of intense anxiety for some faculty (Duke \& Sanchez, 2001). Some faculty members feel discouraged by students' level of writing skill or inability to synthesize and analyze information from professional literary sources (Cowles, Strickland, \& Rodgers, 2001; Devlin \& Slaninka, 1981); however, introducing advanced writing in the nursing curriculum, coupled with use of faculty resources, best serves the longterm interests of both students and faculty. Nursing faculty who do not have access to an on-campus writing seminar may find it helpful to access the variety of WAC information in the literature for ideas on how to incorporate WAC in nursing. Writing and Reading Across the Curriculum (2003) by Behrens and Rosen may prove to be a helpful resource for faculty who are enthusiastic about incorporating WAC in nursing but lack university or college training resources.

\begin{tabular}{|c|c|}
\hline \multicolumn{2}{|l|}{ TABLE 1} \\
\hline \multicolumn{2}{|l|}{ Grading Rubric for Written Integrated Literature Review } \\
\hline Variable & Points \\
\hline Elements of clarity & 40 \\
\hline Economy of expression & 10 \\
\hline Active voice & 10 \\
\hline Parallel expression of parallel ideas & 10 \\
\hline Appropriate voice & 10 \\
\hline Elements of grammar & 40 \\
\hline Subject-verb agreement & 10 \\
\hline Pronoun-antecedent agreement and clarity & 10 \\
\hline Sentence structure (e.g., no fragments or run-ons) & 10 \\
\hline Spelling and punctuation & 10 \\
\hline American Psychological Association format & 60 \\
\hline Title page & 10 \\
\hline Appropriate use of headings & 10 \\
\hline Citations (in-text) & 10 \\
\hline Reference list & 20 \\
\hline Details (e.g., margins, page headers, text justification) & 10 \\
\hline Text of paper & 100 \\
\hline Abstract & 20 \\
\hline Introduction: background and purpose statement & 10 \\
\hline Thesis statement and one main topic per paragraph & 10 \\
\hline $\begin{array}{l}\text { Integration of findings in three articles (i.e., articles not discussed } \\
\text { separately) }\end{array}$ & 25 \\
\hline Logical flow of ideas from introduction to conclusion & 25 \\
\hline Conclusion (summary of main points and implications for nursing practice) & 10 \\
\hline Total & 240 \\
\hline \multicolumn{2}{|l|}{ Comments: } \\
\hline Note. 5 points will be deducted for each page over limit. & \\
\hline
\end{tabular}

The Writing Seminar for teaching assistants at BYU is a half-day training workshop, supplying teaching assistants with the tools they need to help faculty in either grading or providing additional feedback for student papers. In addition, the workshop provides teaching assistants with practice in grading assignments according to a grading rubric. Following the completion of this training, teaching assistants prove to be a valuable resource, especially to nursing faculty who may already have heavy teaching loads and feel they do not have the time to grade written assignments. In the absence of an established training program for teaching assistants, individual colleges or departments of nursing may choose to instead provide their own writing workshop for teaching assistants.

The Writing Fellow Program is a peer-tutoring program designed to help students and faculty with WAC. Writing Fellows are undergraduate students who are exemplary writers, majoring in a variety of disciplines. When working with nursing students, the Writing Fellow reviews each writ- 
TABLE 2

\section{Grading Rubric for Resume Assignment}

\begin{tabular}{lc}
\hline Variable & Points \\
\hline Formatting: professional layout, 1 page in length, 1-inch margins, and & 5 \\
balanced text and white space & 5 \\
Contact information: creative and professional appearance & 5 \\
Objective statement: focused and attention getting & \\
Education and work experience: & 5 \\
Bulleted statements for all applicable categories & 5 \\
Prioritized statements listing most impressive and applicable statements first & 5 \\
Use of action words & 5 \\
Information applicable to requirements in job announcement & \\
Other categories: & 5 \\
Accentuates the positive & 5 \\
Free of spelling and punctuation error & 5 \\
Clear and concise & 5 \\
Logical flow & 55 \\
Total & \\
Comments: & 5 \\
\end{tabular}

ing assignment electronically, and then during a 30-minute one-on-one conference with individual students. Students are then expected to revise the paper again, incorporating the suggestions of the Writing Fellow before submitting to the professor. Even if a university or college does not have a Writing Fellows program in place, nursing faculty could instead choose to partner with the English department, with undergraduate English majors serving as peer tutors for nursing students.

When neither teaching assistants nor collaboration with the English department is available as a resource, nursing faculty may still successfully incorporate WAC principles into course curriculum by using the nursing students themselves to peer review written assignments. In the peer review process, students submit their writing to their peers, who then edit the paper according to guidelines provided by the faculty (Rieber, 2006). Because many student peer reviewers are novices at providing useful feedback on written assignments, faculty must provide peer evaluators with specific and structured checklists to successfully incorporate peer review as an effective evaluation tool (Cho \& Schunn, 2007; Quible, 1997; Rieber, 2006). Nursing faculty may create their own peer review checklists and then make adjustments addressing writing concepts specific to each assignment while simultaneously guiding the peer reviewers in the process of evaluating a paper (Table 1). Ideally, the peer review process should be repeated before submitting the polished assignment to the faculty (Rieber, 2006).

\section{Writing in the Disciplines}

After adopting the WAC philosoconcepts into the nursing curriculum. When incorporated into nursing courses, WID writing assignments introduce students to the language conventions of nursing while simultaneously familiarizing them with the American Psychological Association (APA) formatting (Kiefer \& CSU, 2006d). In essence, students not only learn content specific to the discipline of nursing with WID, but also intellectual skills unique to the field of phy, the next step is to integrate WID nursing (Langer, 1992). Usually, WID assignments are formal, referenced papers prepared over the course of several weeks and adhere to APA formatting.

One of the reasons students report feeling overwhelmed by WID assignments is that often they are unsure of how to begin and how to proceed in creating a good paper (Kiefer \& CSU, 2006c). Nursing faculty can encourage students to be successful writers by creating an assignment that sequences smaller tasks that build toward the final paper or project, and allows time for providing continuous feedback as the students write and rewrite.

Logically sequencing smaller components of a larger writing assignment encourages students to progress during the course of the semester. When grading each of these smaller components, faculty or the teaching assistant should provide ongoing feedback that students can incorporate into their writing, thereby strengthening them as stronger writers and communicators while simultaneously reinforcing that writing is a powerful tool they can use to learn nursing concepts (Moore, 1993). Feedback provided by faculty and teaching assistants are most helpful to students when it comments on both the substance of the assignment and appropriateness of format, grammar, and mechanics (Kiefer \& CSU, 2006a).

Specific WID assignments used in the BYU College of Nursing include an integrated literature review and résumé assignment in the Evidence Based Practice in Nursing and a clinical ethical dilemma assignment, ethical case study assignment, and an ethical debate brief for Nursing Ethics. Each of these assignments requires students to research their topic in the literature, provide references for their key points, and adhere to APA formatting.

Reducing assignments, such as the integrated literature review, into a series of smaller, more manageable assignments that sequentially build on one another will not only be less intimidating for students, but also may activate higher levels of thinking (Lashley \& Wittstadt, 1993). Cou- 
TABLE 3

Grading Rubric for Clinical Ethical Dilemma Journaling Assignment and Ethical Case Study Assignment

\begin{tabular}{|c|c|c|c|c|c|c|}
\hline \multirow{2}{*}{$\begin{array}{l}\text { Variable } \\
\text { Elements of clarity }\end{array}$} & \multicolumn{6}{|c|}{ Points } \\
\hline & & & & & & \\
\hline Economy of expression & 5 & 4 & 3 & 2 & 1 & 0 \\
\hline Active voice & 5 & 4 & 3 & 2 & 1 & 0 \\
\hline Parallel expression of parallel ideas / continuity of point of view and of tense & 5 & 4 & 3 & 2 & 1 & 0 \\
\hline Appropriate use of What? So What? Now What? format & 5 & 4 & 3 & 2 & 1 & 0 \\
\hline \multicolumn{7}{|l|}{ American Psychological Association format } \\
\hline Title page and other considerations & 5 & 4 & 3 & 2 & 1 & 0 \\
\hline Reference page & 5 & 4 & 3 & 2 & 1 & 0 \\
\hline Parenthetical references (citations in text) & 5 & 4 & 3 & 2 & 1 & 0 \\
\hline \multicolumn{7}{|l|}{ Elements of grammar } \\
\hline Subject-verb agreement / Pronoun-antecedent agreement & 5 & 4 & 3 & 2 & 1 & 0 \\
\hline Sentence structure & 5 & 4 & 3 & 2 & 1 & 0 \\
\hline \multicolumn{7}{|l|}{ Evidence of critical thinking } \\
\hline Identification and description of ethical issue & 5 & 4 & 3 & 2 & 1 & 0 \\
\hline Quality of insights & 5 & 4 & 3 & 2 & 1 & 0 \\
\hline Integration of ethical theory(ies), ethical principles, and informal fallacies in thinking & 10 & 8 & 6 & 4 & 2 & 0 \\
\hline Conclusion and implications for clinical practice & 10 & 8 & 6 & 4 & 2 & 0 \\
\hline Total $^{a}$ & 150 & & & & & \\
\hline
\end{tabular}

pling this higher level of thinking with strong communication skills in a written assignment, such as a résumé, provides students with the opportunity to improve practical writing skills pertinent to professionals. As future nurses, it is helpful for students to receive instruction on creatively developing a résumé that successfully highlights their qualifications and communicates skill and potential to a prospective nursing employer.

Written assignments in Nursing Ethics at BYU were carefully designed by the faculty to help nursing students recognize ethical dilemmas in clinical situations, identify and analyze their own feelings regarding an ethical dilemma, strengthen their ability to search the literature for information pertinent to resolving an ethical dilemma, and expand their personal perspectives to consider differing points of view. These written assignments are sequenced in a manner by which each paper becomes more complex during the semester. For example, students are asked to begin with a formal and referenced paper regarding an ethical dilemma witnessed during a clinical rotation. After recognizing and analyzing the ethical dilemma, students are then assigned an ethical case study and asked to research the literature to provide possible solutions. Finally, the students' understanding of ethical principles and theories are challenged during an ethical debate on the topic of their choice. In preparation for the ethical debate, students are required to rely on what they have learned during the first two writing assignments to produce a well-prepared, logical, and referenced argument against their peers.

\section{Writing to Learn}

Essentially, all writing assignments could be called "writing to learn" be- cause the very process of writing encourages and promotes student learning (Hedengren, 1999). Writing to learn activities are usually informal and short writing assignments, such as a journal, summaries, a short answer, or a problem solving idea reinforcing the nursing concepts the students are currently engaged in learning. The possibilities for WTL exercises are almost endless but may include some of the ideas adapted from Berman (1996). Beginning of class activities, lasting 2 to 5 minutes, may include:

- Write down questions from the reading assignment or last class period's lecture material.

- Write down the relationship between yesterday's subject and today's subject.

- Identify what you thought were the most important points of last night's reading.

Middle of class activities, lasting 2 to 5 minutes, may include: 
TABLE 4

\section{Grading Rubric for Ethical Issue Debate}

\begin{tabular}{lr}
\hline Variable & Points \\
\hline Oral presentation & 90 \\
Content: & 10 \\
Assigned part presented comprehensively & 10 \\
Critical thinking evident & 10 \\
Ideas organized and logical & 10 \\
Sources verbally credited & \\
Presentation: &
\end{tabular}

Stayed within time limit

Eye contact (minimum use of notes)

Professional terminology and language

Professional attire

Clarity of expression

Team presentation

Moderator:

Introduction and conclusion

Response to audience questions

Team effectiveness:

Argument for the question

Rebuttal to argument against the question

Argument against the question

Rebuttal to argument for the question

Cohesion of presentation

Response to audience questions

Issue brief

Impartial analysis:

Identification of major points

Impartial presentation

Arguments and rebuttals persuasive:

Argument for

Argument against

Rebuttal to argument for

Rebuttal to argument against

Mechanics:

Sentence structure, grammar, spelling, punctuation

American Psychological Association format for references

- Summarize the concept discussed to this point in today's lecture.
- Ask a question you have about what has been discussed so far in class today.
- Identify the most significant concept learned up to this point in class today.

Writing to learn activities certainly do not need to be reserved for nursing courses also receiving advanced writing credit, but are instead applicable and valuable learning tools that can be easily incorporated into all nursing courses. The amount of writing that takes place in any nursing course is a better predictor of intellectual engagement by the student than any other factor, including the class size (Light, 1992).

\section{Implications for Faculty}

Advanced writing assignments in nursing curriculum can be challenging for faculty, mostly due to time restraints. Accordingly, faculty may feel unsure about whether or not they want to incorporate WAC into their nursing curriculum. Some nursing faculty may say that grading students' papers takes a lot of time; however, in all actuality it is attempting to grade the poorly written paper that takes an extraordinary amount of time. Faculty can reduce the risk of receiving poorly written papers by incorporating WID concepts such as sequencing writing assignments and requiring students to have their papers reviewed first by their peers. An important concept to remember is that a student's writing has the potential for significant improvement, but only when a student receives quality feedback (Hennessy \& Evans, 2005). The process of sequencing steps of an assignment, coupled with opportunities for continual feedback emphasizes writing as a process, instead of writing as a final product (Devlin \& Slaninka, 1981).

Grading rubrics are another timesaving tool for nursing faculty. A wellwritten grading rubric helps speed up the grading process while still offering a good deal of feedback to students. In addition, grading rubrics help students identify each of the writing categories that will be evaluated. A grading rubric is a valuable tool by which a Writing Fellow or teaching assistant can provide initial feedback 
for a student's paper. Grading rubrics can be constructed in various ways, depending on how specific or holistic the grading process is. At the BYU College of Nursing, grading rubrics that provide a specific breakdown of points are commonly used (Tables 2 through 4) to grade student papers.

\section{Conclusion}

Advanced writing assignments in nursing curriculum may seem challenging for faculty; however, WAC, WID, and WTL conceptual coursework for advanced writing can be successfully implemented with careful planning. By implementing foundational writing coursework, nursing students improve critical thinking skills, the capability of personal reflection, and the ability to become effective communicators. Not only do students become stronger written communicators, but they also tend to understand the course material more completely when they are required to write about it.

Writing seminars for faculty and teaching assistants are a valuable resource, as is access to peer-tutoring programs such as Writing Fellows; however, some colleges and universities may not have access to these resources. In such cases, faculty may instead choose to read helpful literature resources, provide their own training to teaching assistants, partner with other departments such as English, or implement peer review to achieve a similar result.

The primary goals of incorporating WAC, WID, and WTL concepts into nursing curriculum are to help nursing students achieve competence in clinically relevant writing assignments; demonstrate critical thinking and communication skills, both oral and written; execute useful literature searches; read and understand research reports; and encourage the incorporation of evidence into clinical practice. With a strong and established writing foundation, nursing students will be more successful in both written and oral communication during the remainder of their nursing program and continuing throughout their nursing career.

\section{References}

American Association of Colleges of Nursing. (1998). The essentials of baccalaureate education for professional nursing practice. Washington, DC: Author.

Behrens, L., \& Rosen, L. (2003). Writing and reading across the curriculum. New York: Longman.

Berman, E. (1996). A short guide to improving student speaking and writing. Tucson: University of Arizona, University Teaching Center.

Callister, L.C. (1993). The use of student journals in nursing education: Making meaning out of clinical experience. Journal of Nursing Education, 32, 185186.

Callister, L.C., Matsumura, G., Lookinland, S., Mangum, S., \& Loucks, C (2005). Inquiry in baccalaureate nursing education: Fostering evidencebased practice. Journal of Nursing Education, 44, 59-64.

Cho, K., \& Schunn, C.D. (2007). Scaffolded writing and rewriting in the discipline: A web-based reciprocal peer review system. Computers \& Education, 48, 409-426.

Cowles, K.V., Strickland, D., \& Rodgers, B. (2001). Collaboration for teaching innovation: Writing across the curriculum in a school of nursing. Journal of Nursing Education, 40, 363-367.

Devlin, K., \& Slaninka, S. (1981). Writing across the curriculum. Journal of Nursing Education, 20, 19-22.

Duke, C.R., \& Sanchez, R. (2001). Assessing writing across the curriculum. Durham, NC: Carolina Academic Press.

Hedengren, E. (1999). What is "writing to learn"? Brigham Young University Writing Matters, 1(2), 1.
Hennessy, D., \& Evans, R. (2005). Reforming writing among students in community colleges. Community College Journal of Research and Practice, 29, 261-275.

Kiefer, K., \& Colorado State University. (2006a). A fuller definition of WID. Retrieved November 24, 2008, from http://wac.colostate.edu/intro/pop6a. cfm

Kiefer, K., \& Colorado State University. (2006b). An introduction to WAC: Basic principles of WAC. Retrieved November 24, 2008, from http://wac.colostate. edu/intro/pop3a.cfm

Kiefer, K., \& Colorado State University. (2006c). Sequencing tasks. Retrieved November 24, 2008, from http://wac. colostate.edu/intro/pop6d.cfm

Kiefer, K., \& Colorado State University. $(2006 \mathrm{~d})$. What is writing in the disciplines? Retrieved November 24, 2008, from http://wac.colostate.edu/intro/ pop2e.cfm

Langer, J.A. (1992). Writing, teaching, and learning in the disciplines. New York: MLA.

Lashley, M., \& Wittstadt, R. (1993). Writing across the curriculum: An integrated curricular approach to developing critical thinking through writing. Journal of Nursing Education, 32, 422-424.

Lassetter, J.H., Luthy, K., Sutherland, C., \& Callister, L. (2005, November). Advanced writing in the College of Nursing. Brigham Young University Writing Matters, 7(3), 1-2.

Light, R.J. (1992). The Harvard assessment seminars, second report. Cambridge, MA: Harvard Graduate School of Education.

Moore, R. (1993). Does writing about science improve learning about science? The Journal of College Science Teaching, 22, 212-217.

Quible, Z.K. (1997). The efficacy of several writing feedback systems. Business Communication Quarterly, 60, 109123.

Rieber, L.J. (2006). Using peer review to improve student writing in business courses. Journal of Education for Business, 81, 322-326.

Slimmer, L. (1992). Effect of writing across the curriculum techniques on students' affective and cognitive learning about nursing research. Journal of Nursing Education, 31, 75-78. 
Copyright of Journal of Nursing Education is the property of SLACK Incorporated and its content may not be copied or emailed to multiple sites or posted to a listserv without the copyright holder's express written permission. However, users may print, download, or email articles for individual use. 